Pacific Journal of Mathematics

BOUNDED SERIES AND HAUSDORFF MATRICES FOR 


\title{
BOUNDED SERIES AND HAUSDORFF MATRICES FOR ABSOLUTELY CONVERGENT SEQUENCES
}

\author{
Philip C. TONNE
}

If $f$ is a function from $[0,1]$ to the complex plane and $c$ is a complex sequence, then the Hausdorff matrix $H(c)$ for $c$ and a sequence $L(f, c)$ are defined:

$$
\begin{aligned}
H(c)_{n p} & =\left(\begin{array}{l}
n \\
p
\end{array}\right) \sum_{q=0}^{n-p}(-1)^{q}\left(\begin{array}{c}
n-p \\
q
\end{array}\right) c_{p+q} \\
L(f, c)_{n} & =\sum_{p=0}^{n} H(c)_{n p} f(p / n) .
\end{aligned}
$$

This paper consists of the following theorem and two converses to it.

Theorem 1. If $A$ is a complex sequence and $\sum_{p=0}^{\infty} A_{p}$ is bounded (there is a number $B$ such that if $n$ is a nonnegative integer then $\left.\left|\sum_{p=0}^{n} A_{p}\right|<B\right), f$ is a function from $[0,1]$ to the complex plane such that if $0 \leqq x<1$ then $f(x)=\sum_{p=0}^{\infty} A_{p} x^{p}$, and $c$ is an absolutely convergent sequence $\left(\sum_{p=0}^{\infty}\left|c_{p+1}-c_{p}\right|\right.$ converges), then $L(f, c)$ converges. Furthermore, if $c$ has limit $d, L(f, c)$ has limit $\sum_{p=0}^{\infty} A_{p}\left(c_{p}-d\right)+f(1) \cdot d$.

Let $\mathscr{F}$ be the collection of all functions $f$ satisfying the hypothesis of Theorem 1. $\mathscr{S}$ be the set of all absolutely convergent sequences. Theorem 1 and its converses show that $\mathscr{F}$ and $\mathscr{S}$ are related in the same way that certain sets of continuous functions are related to certain sets of sequences in [3]. There, for example, the set of functions analytic on the unit disc with power-series absolutely convergent at 1 is shown to be related to the set of bounded sequences.

In Theorem 3 we use the following result due to J. S. MacNerney [2, p. 56] and A. Jakimovski [1], which, incidentally, was used in [3] the relate the set of polynomials to the set of all sequences.

Theorem $A$. If $f$ is a polynomial and $c$ is a complex sequence then $L(f, c)$ converges. Furthermore, if $f(z)=\sum_{p=0}^{n} A_{p} z^{p}$ for each complex number $z$, then $L(f, c)$ has limit $\sum_{p=0}^{n} A_{p} c_{p}$.

The following lemma is useful in the proofs of Theorems 1 and 2.

LEMMA 1. If $M$ is an infinite, complex, lower-triangular matrix, these are equivalent:

(1) There is a positive number $B$ such that if each of $q, n$, and $m$ is a nonnegative integer then $\left|\sum_{p=q}^{m} M_{n p}\right|<B$ and there is a 
sequence $A$ such that, for each nonnegative integer $p$, the sequence $M[, p]$ has limit $A_{p}$.

(2) If $x$ is an absolutely convergent sequence with limit 0 , then $M \cdot x$ converges $\left([M \cdot x]_{n}=\sum_{p=0}^{n} M_{n p} x_{p}\right)$.

Furthermore, if (1) holds and $x$ is an absolutely convergent sequence with limit 0 then $M \cdot x$ has limit $\sum_{p=0}^{\infty} A_{p} x_{p}$.

Proof. First, suppose that (1) holds and that $x$ is an absolutely convergent sequence. If each of $q$ and $m$ is a nonnegative integer, then $\left|\sum_{p=q}^{m} A_{p}\right| \leqq B$ and

$$
\sum_{p=q}^{m} A_{p} x_{p}=\sum_{p=q}^{m}\left(x_{p}-x_{p+1}\right) \sum_{j=q}^{p} A_{j}+x_{m+1} \sum_{j=q}^{m} A_{j},
$$

from which we see that $\sum_{p=0}^{\infty} A_{p} x_{p}$ converges.

If each of $m$ and $n$ is a positive integer, then $(M \cdot x)_{n}-\sum_{p=0}^{m-1} A_{p} x_{p}$ $=\sum_{p=0}^{m-1}\left(M_{n p}-A_{p}\right) x_{p}+\sum_{p=m}^{n}\left(x_{p}-x_{p+1}\right) \sum_{j=m}^{p} M_{n j}+x_{n+1} \sum_{j=m}^{n} M_{n j} \quad$ and, from this, we see that $M \cdot x$ has limit $\sum_{p=0}^{\infty} A_{p} x_{p}$.

Second, suppose that (2) holds. Sequences having the value 1 at one nonnegative integer and 0 at the others show us that there is a sequence $A$ such that, for each nonnegative integer $p$, the sequence $M[, p]$ has limit $A_{p}$.

Let $S$ be the set of all absolutely convergent sequences with limit 0 and let $N$ be a function from $S$ to the numbers such that if $x$ is in $S$ then $N(x)=\sum_{p=0}^{\infty}\left|x_{p}-x_{p+1}\right| . \quad\{S, N\}$ is a complete, normed, linear space.

For each nonnegative integer $n$, let $T_{n}$ be a function from $S$ to the complex numbers such that if $x$ is in $S$ then $T_{n}(x)=(M \cdot x)_{n}$, and note that $T_{n}$ is a continuous linear transformation.

For each $x$ in $S$ the sequence $T(x)$ converges, so that by the "principle of uniform boundedness" there is a number $B$ such that if $n$ is a nonnegative integer and $x$ is in $S$ and $N(x) \leqq 1$ then $\left|T_{n}(x)\right| \leqq B$.

If each of $q$ and $m$ is a nonnegative integer, let $z(q, m)$ be the sequence such that if $p$ is a nonnegative integer, then $z(q, m)=1 / 2$ if $q \leqq p \leqq m$ and $z(q, m)_{p}=0$ otherwise, and notice that $z(q, m)$ is in $S$ and $N(z(q, m)) \leqq 1$.

If each of $m$ and $q$ is a nonnegative integer,

$$
\left|\frac{1}{2} M_{m q}\right|=\left|T_{m}(z(q, q))\right| \leqq B,
$$

and if $n$ is a nonnegative integer,

$$
\left|\frac{1}{2} \sum_{j=q}^{m} M_{n j}\right|=\left|T_{n}(z(q, m+1))-M_{n, m+1} \cdot \frac{1}{2}\right| \leqq 2 B,
$$


and Lemma 1 is proved.

LeMma 2. Suppose that $B>0$ and $v$ is a nondecreasing nonnegative-number-sequence and $b$ is a complex sequence such that if each of $n$ and $q$ is a nonnegative integer then $\left|\sum_{p=q}^{n} b_{p}\right| \leqq B$. Then, if $m$ is a nonnegative integer, $\left|\sum_{p=0}^{m} b_{p} v_{p}\right| \leqq v_{m} B$.

Proof. The lemma is true if $m$ is 0 . Suppose that $m$ is a positive integer such that, for each sequence $b$ as described above, $\left|\sum_{p=0}^{m-1} b_{p} v_{p}\right| \leqq v_{m-1} B$.

Let $a$ be a complex sequence such that if each of $n$ and $q$ is a nonnegative integer, then $\left|\sum_{p=q}^{n} a_{p}\right| \leqq B$. Let $b$ be the sequence such that if $p$ is a nonnegative integer, then $b_{p}=a_{p}$ if $p<m-1$, $b_{m-1}=a_{m-1}+a_{m}$, and $b_{p}=0$ if $p \geqq m$. Then

$$
\begin{aligned}
\left|\sum_{p=0}^{m} a_{p} v_{p}\right| & =\left|\sum_{p=0}^{m-1} a_{p} v_{p}+a_{m} v_{m-1}+a_{m}\left(v_{m}-v_{m-1}\right)\right| \\
& \leqq\left|\sum_{p=0}^{m-1} b_{p} v_{p}\right|+\left|a_{n}\right|\left(v_{m}-v_{m-1}\right) \\
& \leqq B v_{m-1}+B\left(v_{m}-v_{m-1}\right)=B v_{m},
\end{aligned}
$$

and Lemma 2 is proved.

Let us define a matrix $Y$ such that if each of $p$ and $k$ is a nonnegative integer, then

$$
Y_{p k}=\sum_{q=0}^{p}(-1)^{p+q}\left(\begin{array}{l}
p \\
q
\end{array}\right) q^{k},
$$

where we interpret $0^{\circ}$ as 1 . Without proof we state

LEMmA 3. If each of $p$ and $k$ is a nonnegative integer, then $Y_{p+1, k+1}=(p+1)\left(Y_{p k}+Y_{p+1, k}\right) ; Y_{p p}=p ! ; Y_{p k} \geqq 0$ for $p>k$, and, if $n$ is a positive integer $Y_{n, k+1} n^{-k-1} \geqq Y_{n k} n^{-k} ; \lim _{k \rightarrow \infty} Y_{n k} n^{-k}=1$; and, therefore, $Y_{n k} n^{-k} \leqq 1$.

If $n$ is a positive integer, $f$ is a function from $[0,1]$ to the complex plane and $c$ is a complex sequence then

$$
L(f, c)_{n}=\sum_{p=0}^{n} c_{p}\left(\begin{array}{l}
n \\
p
\end{array}\right) \sum_{q=0}^{p}(-1)^{p+q}\left(\begin{array}{l}
p \\
q
\end{array}\right) f(q / n),
$$

and we let $M^{f}$ be a matrix such that if $p$ is a nonnegative integer, then

$$
M_{n p}^{f}=\left(\begin{array}{l}
n \\
p
\end{array}\right) \sum_{q=0}^{p}(-1)^{p+q}\left(\begin{array}{l}
p \\
q
\end{array}\right) f(q / n) .
$$

Proof of Theorem 1. Suppose that $A, f, B$ and $c$ are as in the 
theorem.

Let $n$ be a positive integer.

$$
\begin{aligned}
M_{n n}^{f} & =f(1)+\sum_{q=0}^{n-1}(-1)^{n+q}\left(\begin{array}{l}
n \\
q
\end{array}\right) f(q / n) \\
& =f(1)+\sum_{q=0}^{n-1}(-1)^{n+q}\left(\begin{array}{l}
n \\
q
\end{array}\right) \sum_{k=0}^{\infty} A_{k} q^{k} n^{-k} \\
& =f(1)-\sum_{k=0}^{\infty} A_{k}\left(1-n^{-k} Y_{n k}\right) .
\end{aligned}
$$

If each of $m$ and $q$ is a nonnegative integer $\left|\sum_{p=q}^{m} A_{p}\right| \leqq 2 B$, so that by Lemma 2 and Lemma 3 ,

$$
\left|\sum_{k=0}^{m} A_{k} n^{-k} Y_{n k}\right| \leqq n^{-m} Y_{n m}(2 B) \leqq 2 B,
$$

and

$$
\left|M_{n n}^{f}\right| \leqq|f(1)|+B+2 B=|f(1)|+3 B .
$$

Suppose, now, that $m$ is a nonnegative integer less than $n$.

$$
\begin{aligned}
\sum_{p=0}^{m} M_{n p}^{f} & =\sum_{p=0}^{m}\left(\begin{array}{l}
n \\
p
\end{array}\right) \sum_{k=p}^{\infty} A_{k} n^{-k} Y_{p k} \\
& =\sum_{k=0}^{\infty} A_{k} \sum_{p=0}^{m}\left(\begin{array}{c}
n \\
p
\end{array}\right) n^{-k} Y_{p k} .
\end{aligned}
$$

For each nonnegative integer $k$ let $G_{k}$ be $\sum_{p=0}^{m}\left(\begin{array}{l}n \\ p\end{array}\right) n^{-k} Y_{p k}$ and note that

$$
\begin{aligned}
& n^{k+1}\left[G_{k}-G_{k+1}\right]=\sum_{p=0}^{m} n\left(\begin{array}{l}
n \\
p
\end{array}\right) Y_{p k}-\sum_{p=0}^{m}\left(\begin{array}{l}
n \\
p
\end{array}\right) Y_{p, k+1} \\
& =\sum_{p=0}^{m} n\left(\begin{array}{l}
n \\
p
\end{array}\right) Y_{p k}-\sum_{p=1}^{m}\left(\begin{array}{l}
n \\
p
\end{array}\right) p Y_{p k}-\sum_{p=1}^{m}\left(\begin{array}{l}
n \\
p
\end{array}\right) p Y_{p-1, k} \\
& =\sum_{p=0}^{m}\left[(n-p)\left(\begin{array}{l}
n \\
p
\end{array}\right)-\left(\begin{array}{c}
n \\
p+1
\end{array}\right)(p+1)\right] Y_{p k} \\
& +(n-m)\left(\begin{array}{l}
n \\
m
\end{array}\right) Y_{m k} \\
& =(n-m)\left(\begin{array}{l}
n \\
m
\end{array}\right) Y_{m k} \geqq 0,
\end{aligned}
$$

so that $G$ is a nonincreasing sequence. $G_{0}=1$. The sequence $1-G$ is nondecreasing and nonnegative valued, so that, for each nonnegative integer $r$,

$$
\begin{gathered}
\left|\sum_{k=0}^{r} A_{k}\left(1-G_{k}\right)\right| \leqq 2 B, \\
\left|\sum_{k=0}^{r} A_{k} G_{k}\right| \leqq 4 B,
\end{gathered}
$$


and

$$
\left|\sum_{p=0}^{m} M_{n p}^{f}\right| \leqq 4 B
$$

and $M^{f}$ satisfies condition (1) of Lemma 1.

Let $c$ have limit $d . M \cdot(c-d)$ converges, $L(f, c)=M \cdot(c-d)$ $+L(f, d)$, so that $L(f, c)$ converges with limit $\sum_{p=0}^{\infty} A_{p}\left(c_{p}-d\right)+d \cdot f(1)$.

Theorem 2. Suppose that $f$ is a function from $[0,1]$ to the complex plane and $f$ is continuous on $[0,1)$. Suppose that, for each absolutely convergent sequence $c, L(f, c)$ converges. Then there is a complex sequence $A$ such that $\sum_{p=0}^{\infty} A_{p}$ is bounded and, if $x$ is in $[0,1), f(x)=\sum_{p=0}^{\infty} A_{p} x^{p}$.

Proof. Since each sequence dominated by a geometric sequence with ratio less than 1 is absolutely convergent, we know from [3, Th. 3] that there is a complex sequence $A$ such that if $x$ is in $[0,1)$ then $f(x)=\sum_{p=0}^{\infty} A_{p} x^{p}$, and $A_{p}$ is the limit of the sequence $M^{f}[, p]$.

By Lemma 1 there is a positive number $B$ such that if each of $n$ and $m$ is a positive integer then $\left|\sum_{p=0}^{m} M_{n p}^{f}\right| \leqq B$, and, consequently, $\left|\sum_{p=0}^{m} A_{p}\right| \leqq B$.

THEOREM 3. Suppose that $c$ is an infinite complex sequence such that, for each function $f$, analytic on the unit disc and defined at 1 , such that $\sum_{p=0}^{\infty} f^{(p)}(0) / p$ ! is bounded, $L(f, c)$ converges. Then $c$ is absolutely convergent.

Proof. Suppose that $\sum_{p=0}^{\infty}\left|c_{2 p+1}-c_{2 p}\right|$ is not bounded.

Let $\mathscr{F}_{0}$ be the set of all functions $f$ as described in the theorem such that $f(1)=0$. For each member $f$ of $\mathscr{F}_{0}$ let $N(f)$ be the least number $L$ such that if $n$ is a nonnegative integer then

$$
\left|\sum_{p=0}^{n} f^{p\rangle}(0) / p !\right| \leqq L
$$

$\left\{\mathscr{F}_{0}, N\right\}$ is a complete, normed linear space.

For each positive integer $n$ let $T_{n}$ be the continuous linear transformation from $\mathscr{F}_{0}$ to the plane such that if $f$ is in $\mathscr{F}_{0}$ then $T_{n}(f)$ $=L(f, c)_{n}$. By the "principle of uniform boundedness" there is a number $B$ such that if $f$ is in $\mathscr{F}_{0}$ and $N(f) \leqq 1$ then $\left|T_{n}(f)\right| \leqq B$ for each positive integer $n$.

Let $m$ be a positive integer such that $\sum_{p=1}^{m}\left|c_{2 p+1}-c_{2 p}\right|>2 B$. Let $A$ be a sequence such that $A_{0}=A_{1}=0$ and if $p$ is a positive integer then $A_{2 p+1}=-A_{2 p}=0$ if $c_{2 p+1}=c_{2 p}$ or $p>m$ and 


$$
A_{2 p+1}=-A_{2 p}=\left|c_{2 p+1}-c_{2 p}\right| /\left(c_{2 p+1}-c_{2 p}\right)
$$

otherwise.

Let $f$ be the polynomial such that if $z$ is a complex number then

$$
f(z)=\sum_{p=0}^{m}\left\{A_{2 p+1} z^{2 p+1}+A_{2 p} z^{2 p}\right\} .
$$

$f$ is in $\mathscr{F}_{0}$ and $N(f) \leqq 1$. By Theorem $A$ there is a positive integer $n$ such that

$$
\left|L(f, c)_{n}-\sum_{p=0}^{2 m+1} A_{p} c_{p}\right|<\sum_{p=1}^{m}\left|c_{p 2+1}-c_{2 p}\right|-2 B
$$

so that

$$
\left|L(f, c)_{n}\right|>\left|\sum_{p=0}^{2 m+1} A_{p} c_{p}\right|-\sum_{p=1}^{m}\left|c_{2 p+1}-c_{2 p}\right|+2 B=2 B>B,
$$

which is a contradiction. So $\sum_{p=0}^{\infty}\left|c_{2 p+1}-c_{2 p}\right|$ is bounded.

Similarly $\sum_{p=1}^{\infty}\left|c_{2 p}-c_{2 p-1}\right|$ is bounded. Hence $\sum_{p=0}^{\infty}\left|c_{p}-c_{p+1}\right|$ converges and $c$ is absolutely convergent.

\section{BIBLIOGRAPHY}

1. A. Jakimovski, Some Remarks on the moment-problem of Hausdorff, J. London Math. Soc. 33 (1958), 1-13.

2. J. S. MacNerney, Hermitian moment sequences, Trans. Amer. Math. Soc. 103 (1962), 45-81.

3. P. C. Tonne, Power-series and Hausdorff matrices, Pacific J. Math. 21 (1967), 189-198.

Received January 9, 1968.

EMORY UNIVERSITY 


\title{
PACIFIC JOURNAL OF MATHEMATICS
}

\author{
EDITORS
}

\author{
H. ROYDEN \\ Stanford University \\ Stanford, California
}

\author{
J. P. JANS \\ University of Washington \\ Seattle, Washington 98105
}

\section{J. DUGUNDJI}

Department of Mathematics University of Southern California Los Angeles, California 90007

\section{RICHARD ARENS}

University of California Los Angeles, California 90024

\section{ASSOCIATE EDITORS}

\author{
E. F. BECKENBACH
}

B. H. NEUMANN

F. WoLF

K. YosidA

\section{SUPPORTING INSTITUTIONS}

\author{
UNIVERSITY OF BRITISH COLUMBIA \\ CALIFORNIA INSTITUTE OF TECHNOLOGY \\ UNIVERSITY OF CALIFORNIA \\ MONTANA STATE UNIVERSITY \\ UNIVERSITY OF NEVADA \\ NEW MEXICO STATE UNIVERSITY \\ OREGON STATE UNIVERSITY \\ UNIVERSITY OF OREGON \\ OSAKA UNIVERSITY \\ UNIVERSITY OF SOUTHERN CALIFORNIA
}

\author{
STANFORD UNIVERSITY \\ UNIVERSITY OF TOKYO \\ UNIVERSITY OF UTAH \\ WASHINGTON STATE UNIVERSITY \\ UNIVERSITY OF WASHINGTON \\ AMERICAN MATHEMATICAL SOCIETY \\ CHEVRON RESEARCH CORPORATION \\ TRW SYSTEMS \\ NAVAL WEAPONS CENTER
}

Mathematical papers intended for publication in the Pacific Journal of Mathematics should be in typed form or offset-reproduced, double spaced with large margins. Underline Greek letters in red, German in green, and script in blue. The first paragraph or two must be capable of being used separately as a synopsis of the entire paper. It should not contain references to the bibliography. Manuscripts, in duplicate if possible, may be sent to any one of the four editors. All other communications to the editors should be addressed to the managing editor, Richard Arens, University of California, Los Angeles, California 90024.

Each author of each article receives 50 reprints free of charge; additional copies may be obtained at cost in multiples of 50 .

The Pacific Journal of Mathematics is published monthly. Effective with Volume 16 the price per volume (3 numbers) is $\$ 8.00$; single issues, $\$ 3.00$. Special price for current issues to individual faculty members of supporting institutions and to individual members of the American Mathematical Society: $\$ 4.00$ per volume; single issues $\$ 1.50$. Back numbers are available.

Subscriptions, orders for back numbers, and changes of address should be sent to Pacific Journal of Mathematics, 103 Highland Boulevard, Berkeley 8, California.

Printed at Kokusai Bunken Insatsusha (International Academic Printing Co., Ltd.), 7-17, Fujimi 2-chome, Chiyoda-ku, Tokyo, Japan.

PUBLISHED BY PACIFIC JOURNAL OF MATHEMATICS, A NON-PROFIT CORPORATION

The Supporting Institutions listed above contribute to the cost of publication of this Journal, but they are not owners of publishers and have no responsibility for its content or policies. 


\section{Pacific Journal of Mathematics}

Vol. 26, No. 2 December, 1968

Seymour Bachmuth and Horace Yomishi Mochizuki, Kostrikin's theorem on

Engel groups of prime power exponent ....................

Paul Richard Beesack and Krishna M. Das, Extensions of Opial's inequality ...................................... 215

John H. E. Cohn, Some quartic Diophantine equations .............. 233

H. P. Dikshit, Absolute $(C, 1) \cdot\left(N, p_{n}\right)$ summability of a Fourier series and its conjugate series ............................... 245

Raouf Doss, On measures with small transforms ................. 257

Charles L. Fefferman, $L_{p}$ spaces over finitely additive measures........ 265

Le Baron O. Ferguson, Uniform approximation by polynomials with integral coefficients. II...................................

Takashi Ito and Thomas I. Seidman, Bounded generators of linear

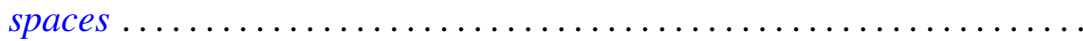

Masako Izumi and Shin-ichi Izumi, Nörlund summability of Fourier series ..........................................

Donald Gordon James, On Witt's theorem for unimodular quadratic

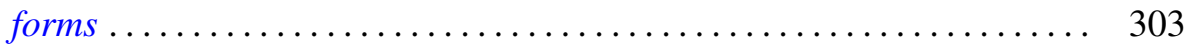

J. L. Kelley and Edwin Spanier, Euler characteristics .............. 317

Carl W. Kohls and Lawrence James Lardy, Some ring extensions with matrix

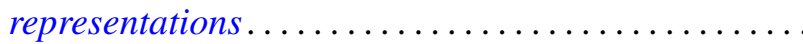

Ray Mines, III, A family of functors defined on generalized primary groups ....

Louise Arakelian Raphael, A characterization of integral operators on the space of Borel measurable functions bounded with respect to a weight function....

Charles Albert Ryavec, The addition of residue classes modulo $n .$.

H. M. (Hari Mohan) Srivastava, Fractional integration and inversion formulae associated with the generalized Whittaker transform ...

Edgar Lee Stout, The second Cousin problem with bounded data ...

Donald Curtis Taylor, A generalized Fatou theorem for Banach

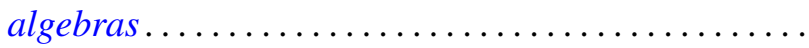

Bui An Ton, Boundary value problems for elliptic convolution equations of Wiener-Hopf type in a bounded region...

Philip C. Tonne, Bounded series and Hausdorff matrices for absolutely convergent sequences... 